\title{
USING PREDICTIVE CONTROLLER TO CONTROL A NONLINEAR SYSTEM
}

This paper engages in the Model Predictive Control of an Air Pressure system. The Air Pressure system includes a pneumatic and an electronic part. The model of the system was created using a tool for systems identifications. Since the system is nonlinear we can use the model linearization and set the constraints to create the Model Predictive Controller in MATLAB environment. The connectivity between PC and the air pressure system is realized by I/O card MF624. We provided the stability test as well. The PID controller was also designed to compare the results with those obtained from the Model Predictive Controller of the mentioned Air Pressure control system.

\section{Introduction}

Predictive control is based on discrete or sampled models of processes. The term "Model Predictive Control" denotes a class of control methods having a set of common properties: a mathematical model of the control system that is used for prediction of the future controlled output, known future trajectory of the required quantity, calculation of sequence of future control actions involving minimization of a proper cost function (usually quadratic) together with future trajectories of control increments and control deviation. Only the first proposed control action is performed and the whole minimization procedure is repeated in the next sampling period again. Usability of predictive control algorithms is quite wide and quality of control is usually higher than in the case of PID-controllers. They are applicable to unstable, multidimensional processes or processes with transport delay or nonlinear systems and compensate effects of measurable and non-measurable failures [1]. The air pressure system is also such a system since a proper algorithm must be used to control the pressure in air pressure system. To make a design of the predictive controller possible the existing air pressure system must be identified first using methods for system identification.

\section{Air pressure system}

The compressor is a small $12 \mathrm{~V}$ powered device. A pneumatic piston is added at the compressor, whereby the output parameter (pressure) is changing. To decrease the air pressure continuously could be possible using a special electronic operating valve. In our system the electromagnetic valve works with discrete control (open/ close) to decrease the pressure in air pressure system. An air tank increases the space for air in the pneumatic system.
The electronic part of the system is centralized in a box. This box incorporates the pressure sensor, protection against excess of pressure, manual switching, LED control and manometer. The overall arrangement of components of the air pressure system is shown in Fig. 1.

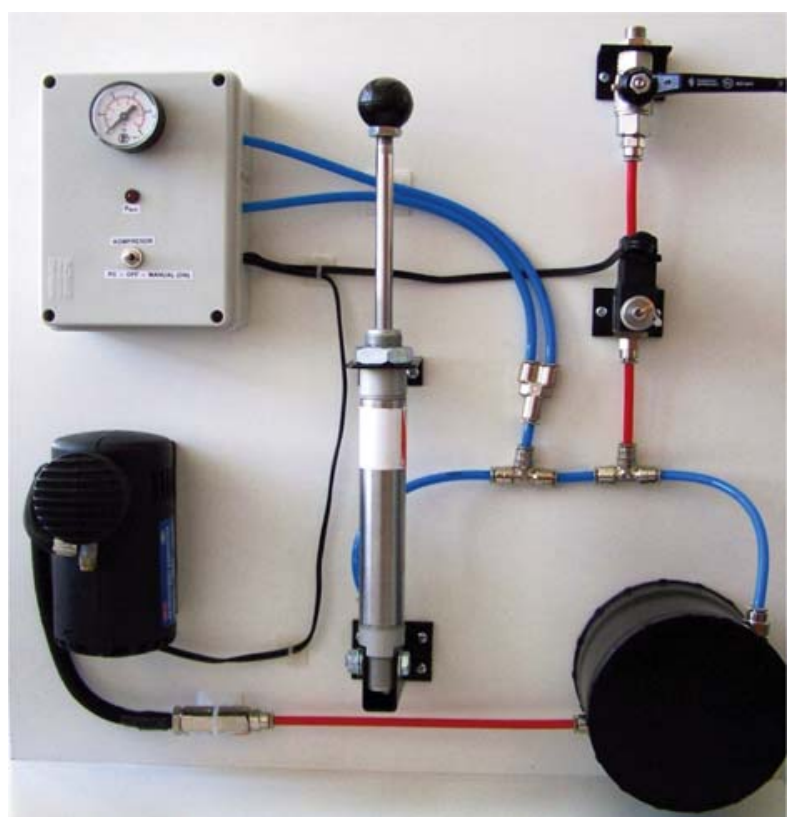

Fig. 1 Air Pressure system

The pneumatic piston can be used to cause a disturbing variable. In the common operation the pneumatic piston is in the high

\footnotetext{
* Jozef Hrbcek, Vojtech Simak, Ales Janota

Department of Control and Information Systems, Faculty of Electrical Engineering, University of Zilina, Slovakia,

E-mail: jozef.hrbcek@fel.uniza.sk
} 
position. First, we can only increase the pressure by pressing the piston; next we can change the pressure inside the system of any size as well. The manual valve (in the upper right corner in Fig 1.) can be used only to decrease the pressure. The pressure inside the system is the output value $y(k)$. The current pressure in the system is sensed by pressure sensor MPX4250AP. The control variables affect the compressor and electromagnetic valve from $\mathrm{I} / \mathrm{O}$ card MF624 through DC converter.

\subsection{Constraints}

In many control applications the desired performance cannot be expressed solely as a trajectory following problem. Many practical requirements are more naturally expressed as constraints on process variables. There are three types of process constraints: Manipulated Variable Constraints: these are hard limits on inputs $u(k)$ to take care of, for example, valve saturation constraints; Manipulated Variable Rate Constraints: these are hard limits on the size of the manipulated variable moves $\Delta u(k)$ to directly influence the rate of change of the manipulated variables; Output Variable Constraints: hard or soft limits on the outputs of the system are imposed to, for example, avoid overshoots and undershoots [7]. We use the Output constraints and Manipulated Variable Constraints.

\subsection{Model linearization}

In some cases the non-linear model can be transformed to linear one utilizing adequate transformation. For example: consider a process described by the following state description:

$$
x(t+1)=f(x(t), u(t)), y(t)=g(x(t)),
$$

The method consists of searching states and outputs of transform functions, for example:

$z(t+1)=A z(t)+B v(t), y(t)=C z(t)$,

This method has two disadvantages: - Functions

$$
z(t)=h(x(t) \text { and } u(t)=p(x(t), v(t),
$$

can be created for few possibilities.

- Constraints, which are usually linear, are transformed to non-linear.

Linearization is used in cases where the model can be linearized by adequate transformation and constraints are considered to be non-linear. Objective function is usually transformed to nonlinear, because it was quadratic in $u(t)$, but not always in $v(t)$. When linear constraints are approximated and objective function was left quadratic the quadratic program for each sample point is the only solution. Linear transform is the only option when both states and input are not deviated from the operation mode. It means that control actions must be closed into their linearized values to preserve the stability. The system robustness can be sacrificed for computational simplicity [2].

\section{Creating the Model Predictive controller}

The predictive controller was created in Simulink environment in MATLAB. Models of the Air Pressure system and compressor were obtained through identification of real equipment. The predictive controller uses the quadratic cost function [4]:

$$
\begin{aligned}
& J\left(N_{1}, N_{u}\right)=\sum_{i-N_{l}}^{N 2} \delta(i)[\hat{y}(t+i \mid t)-w(t+i)]^{2}+ \\
& +\sum_{i=1}^{N_{u}} \lambda(i)[\Delta u(t+i-1)]^{2}
\end{aligned}
$$

where $\hat{y}(t+i \mid t)$ is the predicted output based on the present available information, $w(t+i)$ is the sequence of reference trajectory and $\Delta u(t+i-1)$ is the computed future actions. The parameter $N_{1}$ is the prediction horizon and $N_{u}$ is the control horizon. The coefficients $\delta(i)$ and $\lambda(i)$ are sequences of weights that consider the future behaviour (usually constant values or exponential sequences).

The prediction horizon was set to 100 and the control horizon to 10 . The constraints on manipulated variables were set according to Fig. 2. The control interval was set to $0.3 \mathrm{~s}$. These parameters were determined according to experimental tuning of the controller in MATLAB environment. The Model Predictive controller was compared with the PID controller.

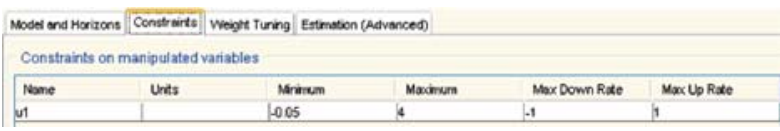

Fig. 2 Sets of the constraints

The control variables were shifted about $4.5 \mathrm{~V}$ according to Fig. 3.

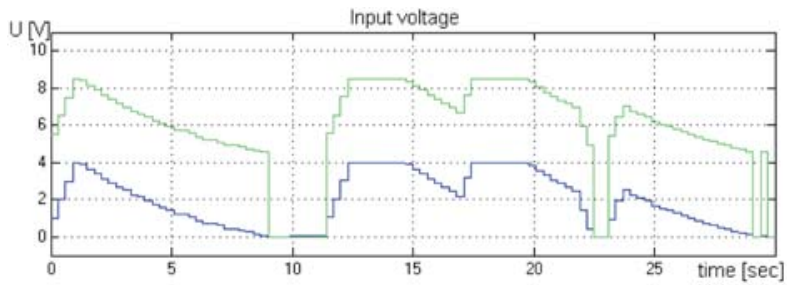

Fig. 3 Shift of control variables

The Fig. 3 shows a block diagram of the predictive closedloop controller. 


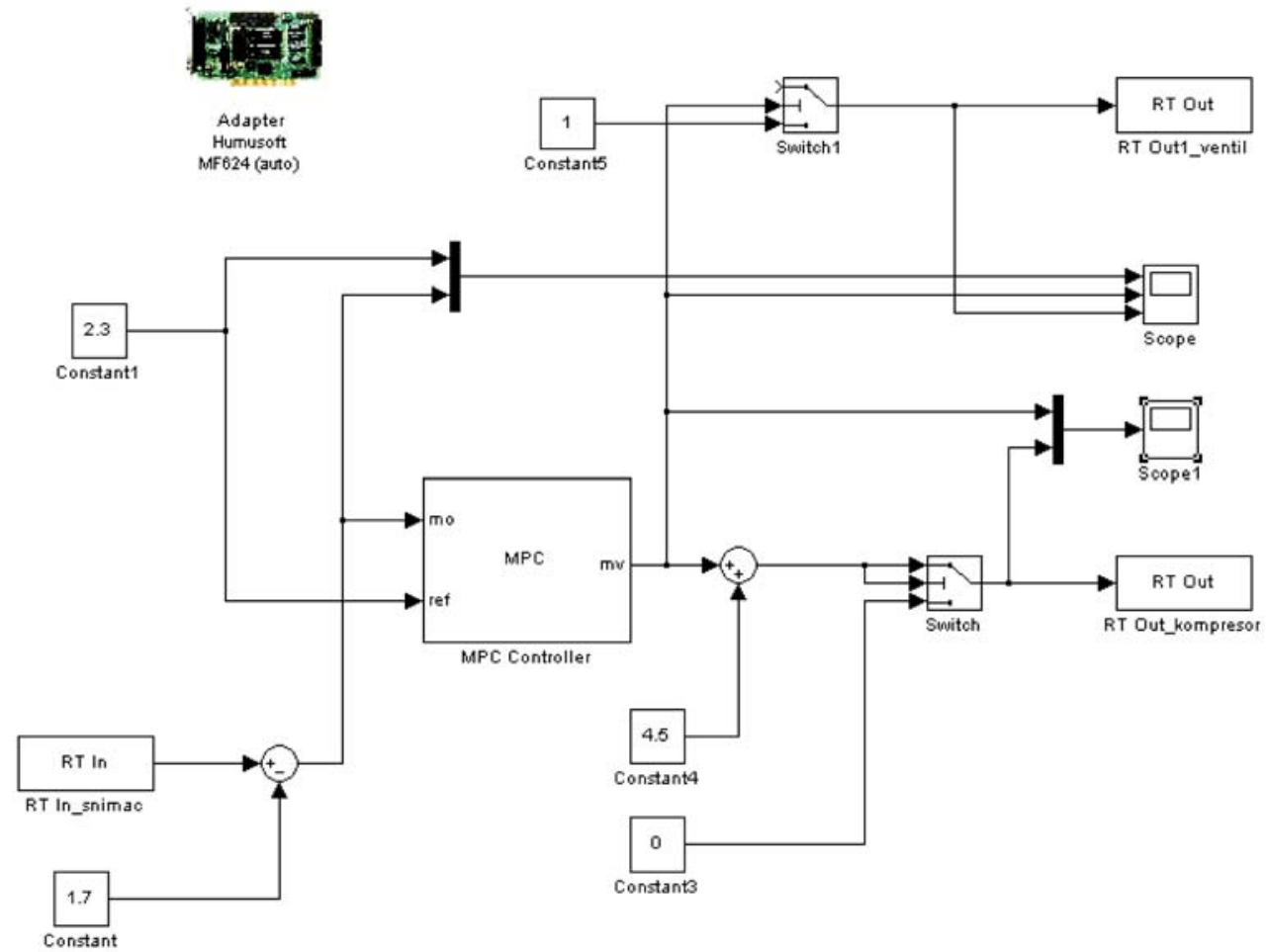

Fig. 4 Closed-loop control of Pressure System using the Predictive Controller

\subsection{Simulations in MATLAB environment}

The presented simulation results are obtained for the required value of pressure $2.2 \mathrm{kPa}$ (blue/black line). The first graph in Fig. 5 shows the pressure inside the Air Pressure system (green/silver values). In the second graph we can see the control values and the last graph shows that the output valve was not switched on.
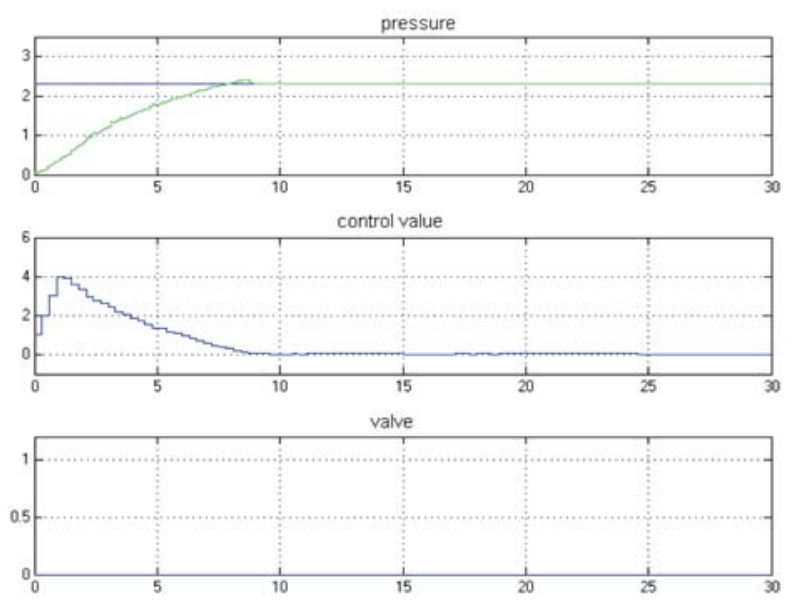

Fig. 5 Simulation results for MPC controller

The second simulation results are obtained for the required value of $2 \mathrm{kPa}$ using the PID controller. The first graph in Fig. 6 shows the pressure inside the Air Pressure system. In the second graph we can see the control values and the last graph shows that the output valve was switched on to decrease air pressure in the system.
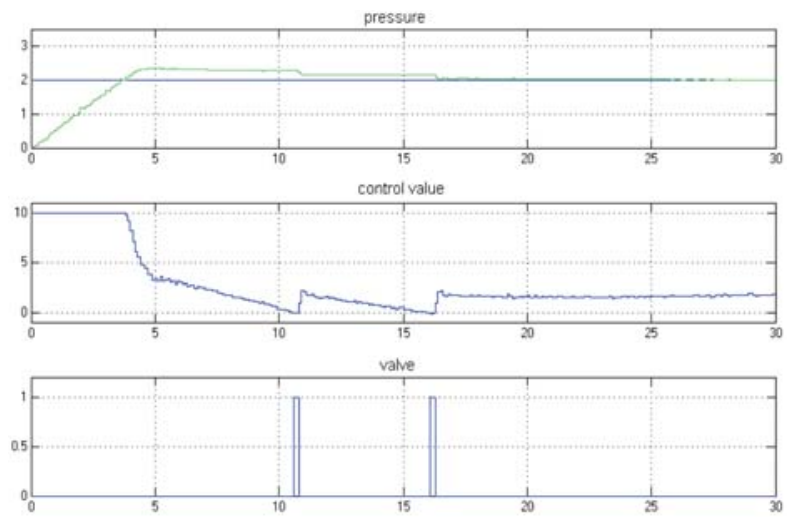

Fig. 6 The results for PID controller

\subsection{Stability and non-linear MPC}

The efficient solution of the optimal control problem is important for any application of non-linear MPC to real processes, but stability of the closed loop is also of crucial importance. Even in the case that the optimization algorithm finds a solution, this fact 
does not guarantee closed-loop stability (even with perfect model match). Several contributions have appeared in recent years, analyzing the regulator problem in a state space framework. The main proposals are the following:

- Infinite horizon. This solution consists of an increase of control and the Prediction horizon to infinity.

- A final limitation. These solutions consist of the final horizon and ensuring stability by adding a state terminal constraint of the form:

$$
x(k+P)=x_{s} .
$$

- Dual control. This idea defines a region around the final state inside which the system could be driven to the final state by means of a linear state feedback controller. The constraint is:

$$
x(t+P) \in \Omega .
$$

The Nonlinear MPC algorithm is used outside this area. The control program switches to the previous calculated linear strategy once the state exceeds $\Omega$ [1].
In our work we used the model linearization. Also, the guarantee of system stability consists of increasing the prediction horizon to a high value.

\section{Conclusion}

The control quality of predictive controller excessively depends on the tuned values of horizons, constraints and weight matrixes as the practical realization showed. The experimental solutions were presented. We made the comparison between PID and MPC controllers. The controller with fixed structure has less accurate result as the MPC controller. Presented MPC controller can be used as a basis for controlling of various real systems.

\section{Acknowledgement:}

This contribution is the result of the project implementation: Centre of excellence for systems and services of intelligent transport, ITMS 26220120028 supported by the Research \& Development Operational Programme funded by the ERDF.

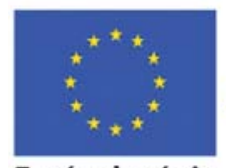

Európska únia

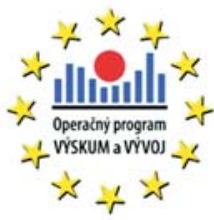

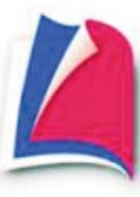

Agentúra

Ministerstva školstva, vedy, výskumu a športu SR pre štrukturálne fondy EÚ

"Podporujeme vyskumne aktivity na Slovensku/Projekt je spolufinancovany zo zdrojov EU."

\section{References}

[1] CAMACHO, E. F., BORDONS, C.: Model Predictive Control. 2nd ed., Springer-Verlag : LondonLimited, 2004, p. 405, ISBN 185233-694-3.

[2] MACIEJOVSKI, J.M.: Predictive Control with Constrains, 2002, p. 331, ISBN 0-201-39823-0.

[3] JOHANSON, R.: System Modeling and Identification, Prentice-Hall, 1993, p. 512, ISBN 0-13-482308-7.

[4] Help in programme MATLAB7, available on the internet (5.4.2010): http://www.mathworks.com/products/mpc/.

[5] HRBCEK, J.: Active Control of Rotor Vibration by Model Predictive Control - a simulation study, In: Report 153, Picaset Oy, Helsinki 2007, ISSN 0356-0872.

[6] NOSKIEVIC, P.: System Modeling and Identification, Ostrava : MONTANEX, a. s., 1999. p. 276, ISBN 80-7225-030-2 (in Czech).

[7] MACIEJOWSKI, J. M.: PREDICTIVE CONTROL with Constraints, Prentice Hall, 2001, p. 102, ISBN 0-201-39823-0.

[8] BUBNICKI, Z.: Modern Control Theory. Springer, 2005, p. 422, ISBN 3-540-23951-0. 